\title{
Patterns of Microbial Heterotrophy Through Changing Environments in a Marine Sediment
}

\author{
J. A. Novitsky ${ }^{1}$ and P. E. Kepkay ${ }^{2 *}$ \\ ${ }^{1}$ Departments of Biology and ${ }^{2}$ Oceanography \\ Dalhousie University, Halifax, Nova Scotia, Canada B3H 4J1
}

\begin{abstract}
Heterotrophic activity was measured through a vertical profile in Halifax Harbor sediments using ${ }^{14} \mathrm{C}$ labeled glucose, glutamate, and lactate as substrates. A modified heterotrophic potential method was used to detect the amount of label that was converted to low molecular weight metabolites as well as the amounts respired to $\mathrm{CO}_{2}$ and incorporated into cellular material. For all three substrates, total uptake was greatest at the transition from aerobic to anerobic sediments $(40 \mathrm{~cm}$ subbottom). The percentage of the total uptake respired reflected the predominant type of heterotrophic metabolism at the various horizons with the highest values occurring above (aerobic respiration) and below (sulfate reduction) the $40 \mathrm{~cm}$ horizon. Incorporation of the substrates into cellular material was low for both glutamate and lactate $(<5 \%)$ but averaged approximately $30 \%$ for glucose. For all three substrates tested, low molecular weight metabolites represented a significant portion of the substrate uptake at many horizons (approximately $50 \%$ at $40 \mathrm{~cm}$ ). Data are presented indicating that the observed increase in heterotrophic activity at $40 \mathrm{~cm}$ sub-bottom may be due to chemoautotrophic organic carbon production at this horizon.
\end{abstract}

\section{INTRODUCTION}

Comparatively little is known about the biological processes in sediments even though they account for a major portion of coastal ecosystems. With bacterial populations as high as $10^{10} \mathrm{~g}^{-1}$, the sediment microbiota outnumber, and may be as important as, the macrobiota. Despite this, microbiology is often the least understood and studied discipline of marine science. Research in sediment microbiology has been focused on the determination of biomass, the nitrogen cycle, sulfate reduction, and methanogenesis. For examples see Erkenbrecher and Stevenson (1975, 1978) and Chrzanowski et al. (1979); Koike and Hattori (1978a, 1978b), Sørensen (1978); and Oren and Blackburn (1979); Cappenberg (1974a, 1974b), and Winfrey and Zeikus (1977), respectively. Only a limited number of studies have measured heterotrophic activity per se (Hanson and Gardner, 1978; Meyer-Reil, 1978; MeyerReil et al., 1978). In addition, there has been only one report on the type and amount of microbial heterotrophic activity through a vertical sequence of marine sediments, where Sørensen et al. (1979) have measured aerobic and anaerobic respiration in the upper $10 \mathrm{~cm}$ of a coastal marine sediment by following oxygen concentrations, nitrogen speciation, and ${ }^{35} \mathrm{SO}_{4}$

- Present address: Scripps Institution of Oceanography, La Jolla, CA 92093, USA

(C) Inter-Research reduction. Moreover, while studies have been reported that measure the aerobic (Meyer-Reil, 1978; MeyerReil et al., 1978) and anaerobic (Hanson and Gardner, 1978) uptake of organic sustrates, there has been no description of heterotrophic activity through a gradient of oxygen concentration such as one is apt to find in most marine sediments.

Recently, Kepkay et al. (1979) and Kepkay and Novitsky (1980) have described autotrophy as well as some physical and chemical parameters in a coastal marine sediment. These sediments are characterized by a relatively deep aerobic zone, a well defined aerobic to anaerobic transition, and an anaerobic zone still within easy reach of sampling. The purpose of the present study, therefore, was to characterize the heterotrophic microbial activity of these sediments under simulated in situ oxygen concentrations using a radioisotope uptake technique that was modified to monitor aerobic as well as anaerobic activity.

\section{MATERIALS AND METHODS}

\section{Sampling}

Diver-collected cores were obtained from Halifax Harbor (Canada) as previously described (Kepkay et al., 1979; Kepkay and Novitsky, 1980) and stored on ice during transport. In the laboratory the cores were split 
and subsamples were taken from the interior of the core at various horizons with modified 5-ml plastic disposable syringes. The subsamples were immediately placed in serum bottles and flushed with mixtures of oxygen and nitrogen. Kepkay and Novitsky's procedures were followed in preparation of the gas mixtures.

\section{Measurement of Heterotrophic Activity}

Relative heterotrophic activity was measured by the single concentration of substrate technique of Griffiths et al. (1977) using ${ }^{14} \mathrm{C}$-(UL)-glucose, specific activity $360 \mathrm{mCi} \mathrm{mmol}^{-1} ;{ }^{14} \mathrm{C}$-(UL)-glutamic acid, specific activity $296 \mathrm{mCl} \mathrm{mmol}{ }^{-1}$; and ${ }^{14} \mathrm{C}$-(UL)-lactic acid, specific activity $138.6 \mathrm{mCi} \mathrm{mmol}^{-1}$. Sediment samples $(1-2 \mathrm{~g})$ were diluted $1: 100$ in filter sterilized bottom water and $10-\mathrm{ml}$ portions of this mixture were placed into serum bottles. Labelled substrate was added to each $(0.05 \mu \mathrm{Ci})$ and the bottles were again capped and flushed with the appropriate air-nitrogen mixture to simulate the in situ $\mathrm{O}_{2}$ concentrations of the sediments. In all cases the amount of labelled substrate added to each bottle exceeded the unlabelled substrate in the slurry. Incubation was at the in situ temperature of $2{ }^{\circ} \mathrm{C}$ for $2 \mathrm{~h}$ before the addition of $1 \mathrm{ml}$ of $3 \mathrm{~N} \mathrm{H}_{2} \mathrm{SO}_{4}$ to stop the reaction. The contents of each incubation were then filtered through Millipore $0.45 \mu$ m filters to collect high molecular weight material. The low molecular weight organics in the filtrates were stored at room temperature and $\mathrm{pH} 1.0$.

\section{Determination of Low Molecular Weight Metabolites}

The amount of substrate that was converted to low molecular weight metabolites was determined by thin layer chromatography of the filtrates from the heterotrophic activity determinations. In general, $100 \mu \mathrm{l}$ of the filtrate was spotted on a thin layer plate next to the spot of the control filtrate (acid killed at time O). After running the chromatogram in the appropriate solvent, the control lane was scraped off in $0.5-\mathrm{cm}$ bands which were placed into scintillation vials and assayed for radioactivity. Once the peak of residual substrate was located, the corresponding area of the test chromatogram was scraped into a scintillation vial. The remaining chromatogram was scraped into another vial and both were assayed for radioactivity. Another control was treated in like manner to determine the background of non-substrate label present. After subtraction of this blank, the ratio of residual substrate to the modified substrate was calculated and the amount of low molecular weight metabolites generated in the course of the incubation was then determined.
Glucose filtrates were run on cellulose coated plates with a solvent consisting of ethyl acetate-pyridinewater, $40: 20: 40$, upper phase only.

Glutamate filtrates were run on silica gel coated plates with a solvent consisting of n-butanol-acetic acid-water, $80: 20: 20$.

Lactate filtrates were run on silica gel coated plates with a solvent consisting of ethanol-chloroform-ammonium hydroxide-water, $53: 303: 15.2$. : 1.5

All chromatograms were run at room temperature and the solvents were allowed to travel $10 \mathrm{~cm}$.

\section{Calculations}

The total amount of substrate taken up was calculated as the sum of the amount of label in cellular material, $\mathrm{CO}_{2}$, and low molecular weight metabolites. Individual components were then expressed as a percentage of this total.

\section{Methane Determination}

Pore water was extracted from the sediments as previously described (Kepkay and Novitsky, 1980). Dissolved methane was measured relative to a seawater standard saturated with methane at $\mathrm{O}^{\circ} \mathrm{C}$ and 1 ATM. The procedure used was the direct injection of $25 \mu \mathrm{l}$ of pore water or standard water onto a molecular sieve (MS 5A) column in a gas chromatograph with an electron capture detector (described by Cooke, 1973). The maximum standard deviation of the methane determinations was $0.002 \mu$ moles $\mathrm{CH}_{4} \mathrm{ml}^{-1}$.

\section{RESULTS}

The relative uptake profiles for the 3 substrates are shown in Figures 1a, 2a and 3a. Data are presented for one representative core only. Data were collected for 2 other cores collected in the same area but on different dates. Comparable uptake profiles from different cores were similar, all showing maximum uptake at the aerobic to anaerobic transition. For all three substrates, the uptake profile is characterized by a single peak of elevated activity at $40 \mathrm{~cm}$ sub-bottom. The glucose profile was assayed at finer depth intervals and showed the same general pattern as glutamate and lactate. Intermediate peaks were not apparent at these finer intervals. The data are presented in Figures 1 to 3 with and without the inclusion of the low molecular weight metabolites produced during the incubation. As can be seen, the inclusion of this material significantly changes the magnitude but not the general 

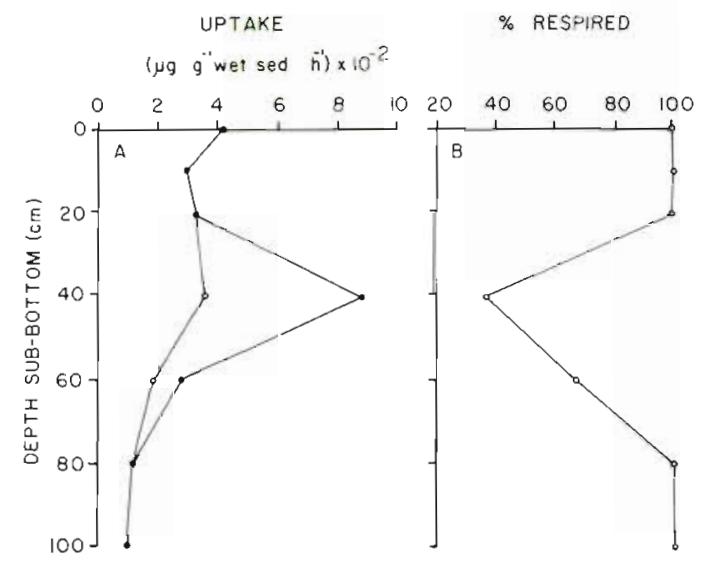

Fig. 1. Uptake and respiration of ${ }^{14} \mathrm{C}$ lactate by microbial populations through a vertical profile of Halifax Harbor sediment. Uptake (A) was calculated in the usual manner () and with the inclusion of low molecular weight metabolites produced during the incubations as determined by chromatography $(\bullet)$. The percent respired (B) was calculated with the inclusion of the low molecular weight metabolites

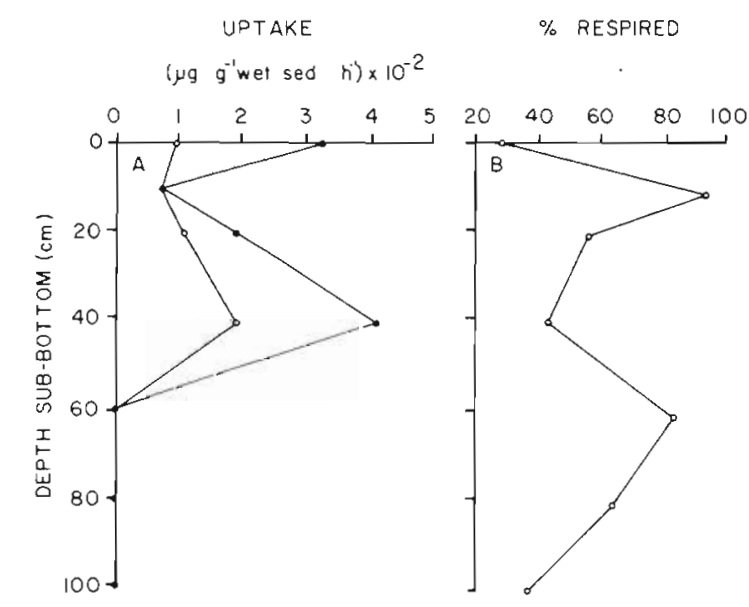

Fig. 2. Uptake and respiration of ${ }^{14} \mathrm{C}$ glutamate by microbial populations through a vertical profile of Halifax Harbor sediment. Uptake (A) was calculated in the usual manner (.) and with the inclusion of low molecular weight metabolites as determined by chromatography $(\bullet)$. The percent respired (B) was calculated with the inclusion of the low molecular weight metabolites

character of the uptake profile. The changes are most pronounced with lactate uptake at the $40 \mathrm{~cm}$ horizon (Fig. 1a) and with glutamate uptake at the 0 and $40 \mathrm{~cm}$ horizons (Fig. 2a). The uptake of both glucose and glutamate show a marked decrease (i. e., of up to 2 orders of magnitude) below $40 \mathrm{~cm}$. When sediment slurries from various depths were incubated under the high oxygen concentrations of room air, the resultant uptake profiles were similar in shape but several times greater in magnitude than those produced under simulated in situ oxygen conditions.

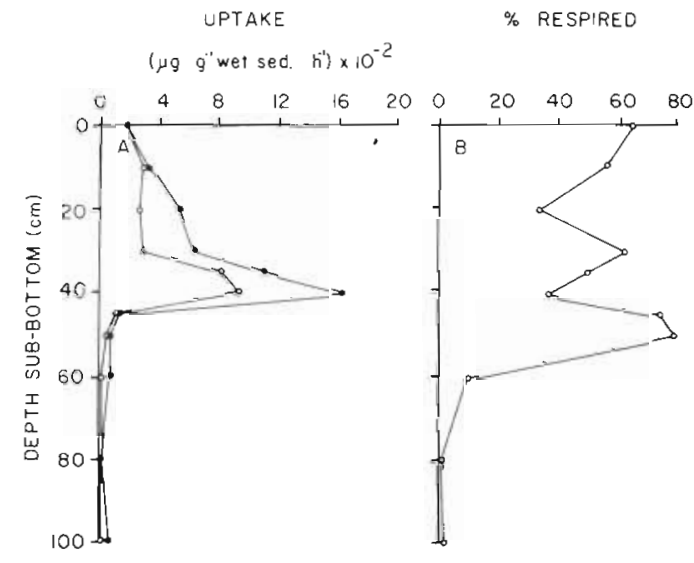

Fig. 3. Uptake and respiration of ${ }^{14} \mathrm{C}$ glucose by microbial populations through a vertical profile of Halifax Harbor sediment. Uptake (A) was calculated in the usual manner ( ) and with the inclusion of low molecular weight metabolites as determined by chromatography $(\bullet)$. The percent respired (B) was calculated with the inclusion of the low molecular weight metabolites

The percentage of the substrate taken up that was converted to cellular materials was low for both lactate and glutamate (less than $5 \%$ ), but averaged about $30 \%$ in the upper horizons when glucose was the substrate (Fig. 3b). In contrast, the percentage of the substrate taken up that was respired to $\mathrm{CO}_{2}$ was very high for lactate (Fig. 1b) and glutamate (Fig. 2b) and moderately high for glucose (Fig. $3 \mathrm{~b}$ ). The percentage of lactate respiration shows a dramatic drop at $40 \mathrm{~cm}$ with nearly $100 \%$ of the label respired above and below. With glutamate as the substrate there was also a drop in the percent respired at $40 \mathrm{~cm}$. However, the results for glucose respiration do not show such a pronounced effect. For both glutamate and glucose, the values for respiration below $40 \mathrm{~cm}$ are shown, but with the total uptake very low it is questionable whether these figures are valid. The amount of substrate converted to low molecular weight metabolites varies from 0 to $70 \%$ for all three substrates. Since the incorporation of labelled lactate or glutamate into cellular material was low, the results for conversion to low molecular weight metabolites are essentially a mirror image of the respiration results. When lactate was used as a substrate, low molecular weight metabolites were only detected at 40 and $60 \mathrm{~cm}$, while for glutamate these metabolites were found throughout the profile and were especially high at $0(70 \%)$ and $40 \mathrm{~cm}(54 \%)$. With glucose as the substrate, low molecular weight metabolites varied from 0 to $50 \%$ with no apparent pattern throughout the profile. As an example, the breakdown of substrate utilization at the $40 \mathrm{~cm}$ horizon for all 3 substrates is shown in Table 1.

A profile of dissolved methane in the pore water of these sediments is shown in Figure 4. No methane was 
Table 1 Fate of labelled substrate taken up by the microbial population from the $40-\mathrm{cm}$ transitional enviroment

\begin{tabular}{|c|c|c|c|}
\hline \multirow[t]{2}{*}{ Substrate } & \multicolumn{3}{|c|}{$\begin{array}{c}\text { Percentage of substrate taken up } \\
\text { associated with: }\end{array}$} \\
\hline & Respiration & $\begin{array}{l}\text { Cellular } \\
\text { macro- } \\
\text { molecules }\end{array}$ & $\begin{array}{c}\text { Low molecular } \\
\text { weight } \\
\text { metabolites }\end{array}$ \\
\hline Glucose & 36.4 & 21.0 & 42.6 \\
\hline Glutamate & 43.6 & 3.3 & 53.1 \\
\hline Lactate & 36.3 & 4.2 & 59.5 \\
\hline
\end{tabular}

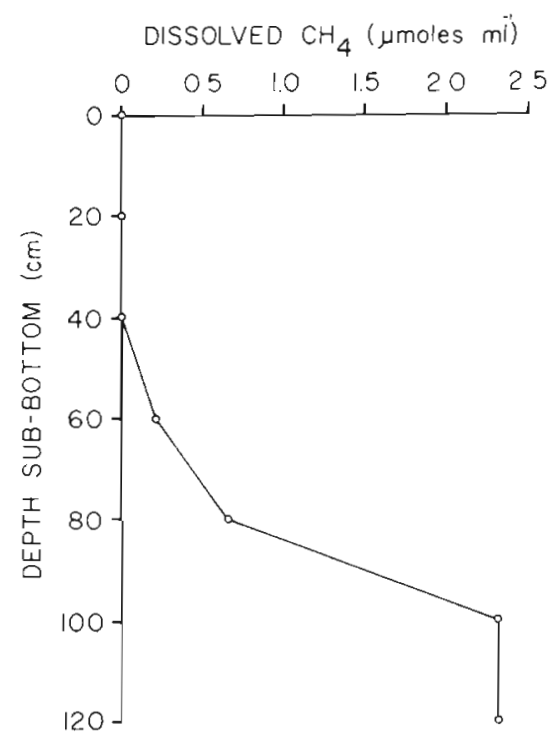

Fig. 4. Profile of the concentration of dissolved methane in pore water of Halifax Harbor sediments. Methane concentrations were determined by gas chromatography. Twice the maximum standard deviation $\left(0.002 \mu\right.$ moles $\left.\mathrm{ml}^{-1}\right)$ is smaller than the diameter of data points

detected above $40 \mathrm{~cm}$; below $40 \mathrm{~cm}$ methane was detected in increasing amounts down to $100 \mathrm{~cm}$ where it reached saturation levels.

\section{DISCUSSION}

To assess the relative microbial activity in these sediments we chose the single substrate concentration method of Griffiths et al. (1977). This procedure has well-defined limitations. The concentration of labelled substrate is usually in excess of the unlabelled substrate concentration so that the potential rather than the actual uptake rate is determined. However, the method can be used to compare heterotrophic activity in profile through a sediment. With this in mind, the $\mathrm{V}$ max of substrate uptake calculated by Kepkay and Novitsky (1980) and Novitsky and Kepkay (unpub- lished), using Griffiths et al.'s (1974) modification of the technique of Wright and Hobbie (1966), compare well to the data presented here. An attempt was made to determine the uptake rate using undisturbed sediment cores according to the method of Meyer-Reil (1978), but the compact nature of these fine-grained sediments prevented the infiltration of substrate even when high vacuum was applied.

Previously, all methods for the determination of the heterotrophic activity of seawater or marine sediments ignored the possibility of conversion of labelled substrate to anything but $\mathrm{CO}_{2}$ or cellular material. This may be the case in many aerobic systems. However, it seems likely that in areas of reduced oxygen concentration or in anaerobic areas that fermentation end products would constitute a large portion of the substrate uptake as has been demonstrated by Christian and Wiebe (1978) for salt marsh soils. Using the chromatographic method described here, we were able to detect large amounts of labelled material that were not retained by filtration, i. e. low molecular weight metabolites. Due to the chemical heterogeneity of this material we were unable to identify its components. It should contain both intracellular (pool material and low molecular weight metabolites) and extracellular (metabolic and products and leakage) material. Measurements of this kind are of obvious importance because this material would contribute directly to the pool of dissolved organic carbon in the natural environment.

The gross uptake of the three substrates by these sediments is characterized by a large peak of activity at the transition from aerobic to anaerobic sediments $(40 \mathrm{~cm}$ sub-bottom). This is also the area where a peak in bacterial cell numbers (determined by acridine orange direct counts) occurs (Kepkay et al., 1979). The specific activity index proposed by Wright (1978) attempts to correct activity values for changes in population size by dividing the measured activity by bacterial numbers. The resulting index should give an estimate of activity based on factors other than population size. We have calculated the indices for glutamate, glucose and lactate uptake and have found that only the uptake of lactate is closely related to population size. The specific activity of lactate uptake is independent of depth, indicating uniform uptake per unit population throughout the sediments examined. However, bacterial numbers in themselves are often no indication of a population's activity. Kepkay et al. (1979) and Kepkay and Novitsky (1980) have shown that this transitional environment is also active with respect to the chemoautotrophic production of organic carbon. Using our previous methods (Kepkay et al., 1979: Kepkay and Novitsky, 1980) for detecting $\mathrm{CO}_{2}$ fixation, but stopping the reaction with rapid filtration 
rather than acidification, it was found that $49 \%$ of the organic carbon fixed by populations from the $40 \mathrm{~cm}$ horizon was present extracellularly (Novitsky and Scott, unpublished). This means that there is a constant production of dissolved organic matter available for microbial populations. We feel that this is the major, if not the paramount, factor responsible for the elevated cell numbers and activity at this horizon. It must be emphasized, however, that the contribution by bacterial biomass to the organic carbon content of the sediment at this and other horizons is very small. The bacterial biomass contributes little (i. e., less than $1 \%$ ) to the organic pool (Kepkay and Novitsky, 1980) and as such it cannot greatly influence the biology and/or chemistry of these sediments. This small biomass does not preclude a significant bacterial role in biochemical transformations. As an example, we have shown the chemoautotrophic generation of organic carbon at the $40 \mathrm{~cm}$ horizon to be $1.4 \times 10^{-2} \mu \mathrm{g} \mathrm{g}^{-1}$ wet sediment $\mathrm{h}^{-1}$ (Kepkay and Novitsky, 1980). When the sedimentation rate of only $2.5 \mathrm{~mm} \mathrm{yr}^{-1}$ is considered, the residual organic carbon at $40 \mathrm{~cm}$ is a reflection of long-term accumulation in situ rather than the expression of a point-in-time population of bacteria.

Below the $40-\mathrm{cm}$ horizon, uptake activity under simulated in situ anaerobic conditions for glucose and glutamate falls by 2 orders of magnitude indicating that these are probably not the normally encountered substrates in vivo. Stimulation of glucose and glutamate uptake by the addition of oxygen indicates that populations are present which are capable of taking up these substrates even though they may be dormant under in situ conditions. The horizons immediately below $40 \mathrm{~cm}$ are active with respect to sulfur reduction (Kepkay and Novitsky, 1980) and exhibit active uptake of lactate, a preferred substrate for sulfur reducing bacteria. Lactate, other fermentation end products, and short chain fatty acids can all be converted, through a number of steps, to methane (Cappenberg, 1976). The eventual production of methane may also be contributing to the sustained uptake of lactate below $60 \mathrm{~cm}$. Since strict anaerobic techniques (Hungate, 1969) were not followed, the only evidence for methanogenesis is the presence of methane (Fig. 4). Again, this may be more indicative of the long-term accumulation of end products rather than intensive short-term production.

The only apparant anomaly in uptake patterns is the enhanced uptake of glutamate just below the mudwater interface. This enhanced activity can only be detected then the low molecular weight fraction is included in the uptake calculations. Quite possibly, the cells - limited with respect to nitrogen as suggested by Kepkay and Novitsky (1980) - are deaminating the glutamate for a nitrogen source and discarding the carbon skeleton. Because there are many other possibilities, the exact reason for this enhanced uptake remains unknown.

The data reflecting the fate of the substrate after uptake demonstrate that a pattern of microbial metabolism exists that is related to the various environments encountered in vertical section through these sediments. Incorporation of lactate and glutamate into cellular carbon was very low $(<5 \%)$. This is especially surprising in the case of glutamate, which is an amino acid that one would expect to be easily incorporated into protein. Incorporation of glucose is much higher (averaging $30 \%$ ) and may be due to the versatility of this central metabolite. The presence of soluble low molecular weight material was most pronounced in and near the aerobic-anaerobic transition and, assuming the amount of intracellular pool and metabolite material to be small, most of this carbon would therefore be excreted metabolic and products. Considering the reduced amount of oxygen at the transition, one would expect fermentation to be the predominant type of metabolism in this area. This conclusion is supported by the fact that the percent respired for all three substrates is low at the horizon. Above and below the transition, the percent respired for glutamate and especially lactate is nearly $100 \%$,

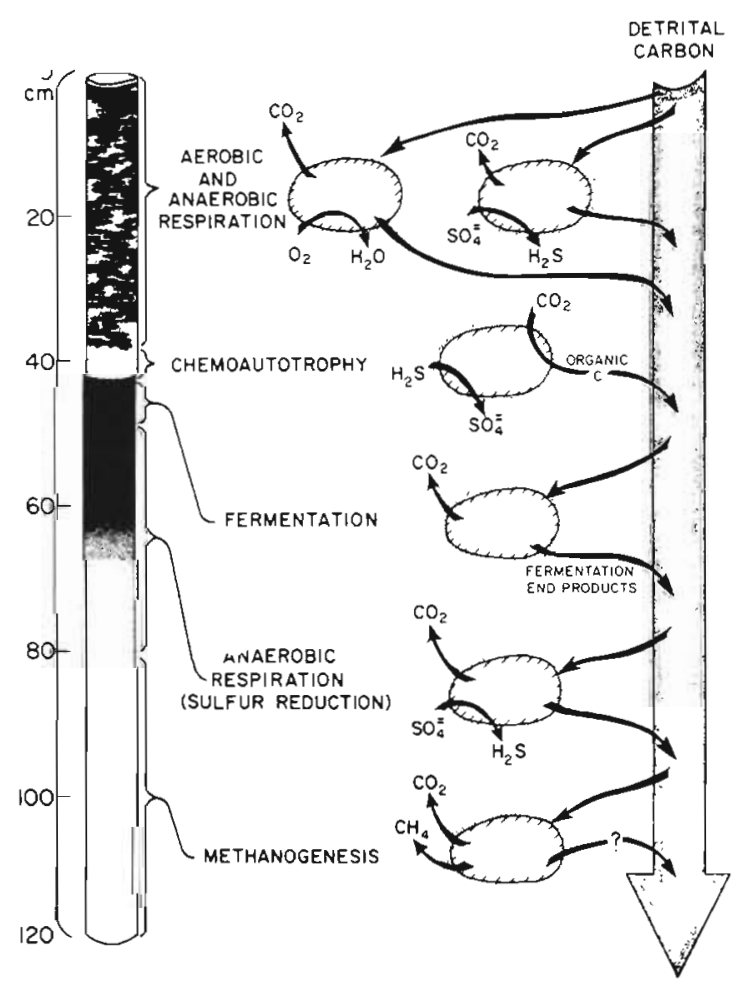

Fig. 5. Schematic diagram of microbial metabolism and carbon flow in Halifax Harbor sediments. Only the predominant type of metabolism is listed for the various horizons. This does not imply that they are exclusive or nonoverlapping 
indicating aerobic respiration and anaerobic respiration (sulfate reduction), respectively. The percent of glucose respired follows a somewhat similar pattern with a low value at $40 \mathrm{~cm}$ and higher values immediately below; this indicates that $\mathrm{CO}_{2}$ is probably produced at the aerobic to anaerobic transition by predominately fermentative metabolism. A clear explanation of the percentage of glucose respired in the overlying aerobic zones is masked by the relatively large amount of substrate that is converted into cellular material. Our data do not compare well with those of Meyer-Reil (1978) (an average of $8 \%$ of aerobic glucose uptake respired) or Hanson and Gardner (1978) (20 to $50 \%$ of anaerobic alanine uptake respired and 5 to $20 \%$ of anaerobic asparate uptake respired). The reasons for the large discrepancy probably reflect the diverse types of sediments studied: a sandy beach (Meyer-Reil, 1978), a salt marsh (Hanson and Gardner, 1978), and the ponded muds of this study. It is clear then that sedimentary environments must be taken into account before any meaningful comparison of microbial activity in these environments can be made.

The general succession of microbial metabolism in the Halifax Harbor sediments is summarized diagrammatically in Figure 5. One of the primary factors governing this succession is the availability of oxygen and sulfate as terminal electron acceptors. The various groups of heterotrophs not only mineralize the organic carbon pool but are also active in changing its composition through their metabilism. The constant production of organic carbon by chemoautotrophy at the transition between aerobic and anaerobic sediments fuels the active heterotrophic populations. Actual bacterial biomass, as evident in direct measurements and the incorporation of labelled substrates, is insignificant with respect to the organic carbon pool in these sediments.

Acknowledgements. For expert diving and field services the authors wish to acknowledge the Richard W. Welsford Research Group, Ltd., especially Rick Welsford, Lloyd Crocker, and Bruce Gibson. We are also indebted to Jean Novitsky and lan Scott for superb technical assistance.

This research was initiated by a grant from the Dalhousie Research Development Fund for the Sciences and continued with support from grants A-6548 and G-0078 from the National Research Council of Canada.

\section{LITERATURE CITED}

Cappenberg, Th. E. (1974a). Interrelations between sulfatereducing and methane-producing bacteria in bottom deposits of a freshwater lake. I. Field observations. Antonie van Leeuwenhoek 40: 285-295

Cappenberg, Th. E. (1974b). Interrelations between sulfate- reducing and methane-producing bacteria in bottom deposits of a freshwater lake. II. Inhibition experiments. Antonie van Leeuwenhoek 40: 297-306

Cappenberg, Th. E. (1976). Methanogenesis in the bottom deposits of a small, stratifying lake. In: Schlegel, H. G., Gottschalk, G., Pfennig, N. (eds) Symposium on the microbial production and utilization of gases $\left(\mathrm{H}_{2}, \mathrm{CH}_{4}, \mathrm{CO}_{2}\right)$. E. Goltze KG, Göttingen, pp. 125-134

Christian, R. R., Wiebe, W. J. (1978). Anaerobic microbial community metabolism in Spartina alterniflora soils. Limnol. Oceanogr. 23: 328-336

Chrzanowski, T. H., Stevenson, L. H., Kjerfve, B. (1979). Adenosine 5 '-triphosphate flux through the north inlet marsh system. Appl. Environ. Microbiol. 37: 841-848

Cooke, R. C. (1973). The use of activated charcoal for the removal of oxygen from gas systems. Limnol. Oceanogr. 18: $150-152$

Erkenbrecher, C. W., Stevenson, L. H. (1975). The influence of tidal flux on microbial biomass in salt marsh creeks. Limnol. Oceanogr. 20: 618-625

Erkenbrecher, C. W., Stevenson, L. H. (1978). The transport of microbial biomass and suspended material in a highmarsh creek. Can. J. Microbiol. 24: 839-846

Griffiths, R. P., Hanus, F. J., Morita, R. Y. (1974). The effects of various water treatments on the apparent uptake of glutamic acid by natural marine microbial populations. Can. J. Microbiol. 20: 1261-1266

Griffiths, R. P., Hayasaka, S. S., McNamara, T. M., Morita, R. Y. (1977). Comparison between two methods of assaying relative microbial activity in marine environments. Appl. Environ. Microbiol. 34: 801-805

Hanson, R. B., Gardner, W. S. (1978). Uptake and metabolism of two amino acids by anaerobic microorganisms in four diverse saltmarsh soils. Mar. Biol. 46: 101-107

Hungate, R. E. (1969). A roll tube method for the cultivation of strict anaerobes. In: Norris, J. R., Ribbons, D. W. (eds) Methods in microbiology, Vol. 3B. Academic Press Inc., New York, pp. 101-107

Kepkay, P. E., Cooke, R. C., Novitsky, J. A. (1979). Microbial autotrophy: A primary source of organic carbon in marine sediments. Science, N. Y. 204: 68-69

Kepkay, P. E., Novitsky, J. A. (1980). Microbial control of organic carbon in marine sediments: Coupled chemoautotrophy and heterotrophy. Mar. Biol. 55: 261-266

Koike, I., Hattori, A. (1978a). Denitrification and ammonia formation in anaerobic coastal sediments. Appl. Environ. Microbiol. 35: 278-282

Koike, I., Hattori, A. (1978b) Simultaneous determination of nitrification and nitrate reduction in coastal sediments by a ${ }^{15} \mathrm{~N}$ dilution technique. Appl. Environ. Microbiol. 35: $853-857$

Meyer-Reil, L.-A. (1978). Uptake of glucose by bacteria in the sediment. Mar. Biol. 44: 293-298

Meyer-Reil, L.-A., Dawson, R., Liebezeit, G., Tiedge, H. (1978). Fluctuations and interactions of bacterial activity in sandy beach sediments and overlying waters. Mar. Biol. 48: 161-171

Oren, A., Blackburn, T. H. (1979). Estimation of sediment denitrification rates at in situ nitrate concentrations. Appl. Environ. Microbiol. 37: 174-176

Sørensen, J. (1978). Capacity for denitrification and reduction of nitrate to ammonia in a coastal marine sediment. Appl. Environ. Microbiol. 35: 301-305

Sørensen, J., Jørgensen, B. B., Revsbech, N. P. (1979). A comparison of oxygen, nitrate, and sulfur respiration in coastal marine sediments. Microbial Ecology 5: 105-115 
Winfrey, M. R., Zeikus, J. G. (1977). Effect of sulfate on carbon and electron flow during microbial methanogenesis in freshwater sediments. Appl. Environ. Microbiol. 33: 275-281

Wright, R. T. (1978). Measurement and significance of specific activity in the heterotrophic bacteria of natural waters. Appl. Environ. Microbiol. 36: 297-305

Wright, R. T., Hobbie, J. E. (1966). Use of glucose and acetate by bacteria and algae in aquatic ecosystems. Ecology 47 : $447-464$

This paper was presented by Professor P. J. Wangersky; it was accepted for printing on September 3, 1980 